\title{
Experimental and theoretical study of quercetin complexes formed on pure silica and Zn-modified mesoporous MCM-41 and SBA-16 materials
}

\author{
Margarita Popova $^{\mathrm{a}^{*}}$, Ivalina Trendafilova ${ }^{\mathrm{a}}$, Ágnes Szegedi ${ }^{\mathrm{b}}$, Judith Mihály $^{\mathrm{b}}$, Peter Németh ${ }^{\mathrm{b}}$, \\ Sylvia G. Marinova ${ }^{c, d}$, Hristiyan A. Aleksandrov ${ }^{c}$, Georgi N. Vayssilov ${ }^{c}$

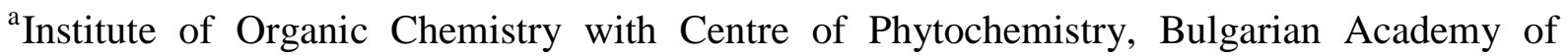 \\ Sciences, 1113, Sofia, Bulgaria \\ ${ }^{\mathrm{b}}$ Research Centre for Natural Sciences, Institute of Materials and Environmental \\ Chemistry, Hungarian Academy of Sciences, 1117, Budapest, Magyar tudósok körútja 2, \\ Hungary \\ ${ }^{\mathrm{c}}$ Faculty of Chemistry and Pharmacy, University of Sofia, 1126, Sofia, Bulgaria \\ ${ }^{\mathrm{d}}$ Faculty of Biology, University of Sofia, 1164, Sofia, Bulgaria \\ * Corresponding author. \\ E-mail address: mpopova@orgchm.bas.bg (M. Popova).
}

\begin{abstract}
SBA-16 and MCM-41 silica materials were synthesized and modified by post-synthesis method with different amounts of Zn (2 and 4 wt.\%). Quercetin, a flavonol compound, was loaded by incipient wetness impregnation method on the pure silica and $\mathrm{Zn}$-modified mesoporous MCM-41 and SBA-16 supports. The parent and drug loaded formulations were characterized by powder XRD, $\mathrm{N}_{2}$ physisorption, thermal analysis, TEM, UV Vis and FT-IR spectroscopies. The formation of Zn:quercetin complex was studied by FT-IR spectroscopy and quantum-chemical calculations. Loading of quercetin on mesoporous carriers made the sustained delivery of the bioactive compound possible in a buffer with $\mathrm{pH}=5.5$, typical of dermal formulations. The results from the release experiments are in good accordance with the inter-action energy between the bioactive molecule and non-modified and $\mathrm{Zn}$-modified mesoporous materials, predicted by the quantum-chemical calculations. For the first time the formation of the most stable $\mathrm{Zn}$ quercetin complexes loaded on the mesoporous silica materials were determined. The obtained mesoporous delivery systems with $\mathrm{Zn}$-quercetin complex are promising as dermal formulations.
\end{abstract}




\section{Introduction}

Quercetin (2-(3',4'-dihydroxyphenyl)-3,5,7-trihydroxy-4H-chromen-4-one) ( Scheme 1) is a natural flavonol, which can be isolated from apples, wine, berries and tea. It has been extensively studied because of its biological and pharmaceutical properties and possible medicinal applications [1-4]. The published data concerning the study of quercetin have been rapidly expanding in the last ten years, owing to its role in the treatment and prevention of many diseases.

Flavonols demonstrate wide biological and pharmacological properties such as anti-cancer, anti-inflammatory, anti-diabetic, antiviral, anti-allergic, antimutagenic, lipid peroxidation inhibitory activity, etc. Quercetin attracts considerable interest because of its numerous biological properties. Its use as a health promoting agent is hindered by its low solubility in water and high instability in a neutral and alkaline medium. In order to solve the problems of quercetin's bioavailability and to increase its efficacy, various approaches like preparation of delivery systems including liposomes [5], nanostructured lipid carriers [6,7], cyclodextrin complexation [8], nanoparticles [9,10], metal ions complexes [11,12], have been employed. Different approaches towards the preparation of suit-able delivery systems were applied depending on the target place.

Research of quercetin incorporation in lipid carriers shows controlled release and higher bioavailability. Oral application of lipid-quercetin systems leads to an increased concentration of the flavonoid in the lungs, kidney and liver compared to pure quercetin. A pH-dependent controlled release of quercetin was achieved by hybrid systems of liposomes and biodegradable polymers (hyaluronic acid, chitosan). The system allows the delivery of bioactive molecules to the intestinal tract, avoiding burst release in the lower $\mathrm{pH}$ in the stomach. This way quercetin can be used for the neurological diseases treatment of oxidative stress and inflammation related disorders in the intestinal tract [13]. There is information that delivery systems based on liposomes improve the transdermal diffusion of hydrophobic antioxidants like quercetin [13]. Histopathological analysis shows that these systems protect the skin from photo-damage caused by UVB radiation as well [14].

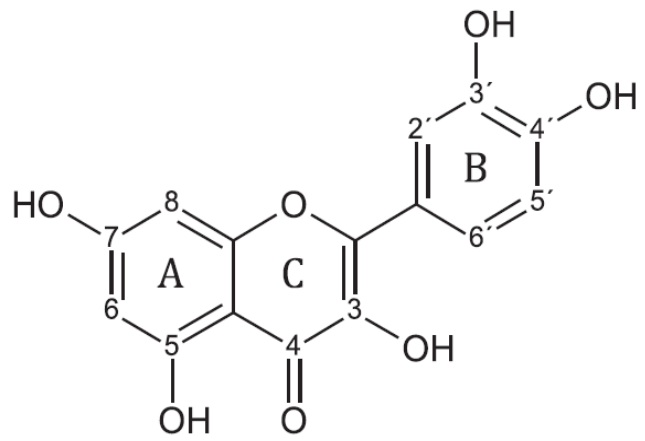

Scheme 1. Molecular structure of quercetin. 
Advantages of the mesoporous silicas, such as high specific surface area, tunable pore size, controlled particle size and morphology, large pore volumes, uniform porosity, stable aqueous dispersion, excellent biocompatibility, and in vivo biodegradability make them promising materials for the preparation of delivery systems of bioactive molecules [15-20]. Mesoporous nanosized silicas ensure the facile functionalization with different organic groups, and/or metal ions, making them very promising candidates for a wide range of biomedical purposes, such as controlled drug delivery, bone tissue regeneration, cell tracking and immobilization of proteins or enzymes [18-20]. They have been proposed for the first time as carriers for drug delivery in 2001 by Vallet-Regí et al. [16]. Mesoporous silica materials also fulfil the conditions for homogenous distribution of the drug through the matrix in contrast to the conventionally used polymeric materials. The appropriate chemical surface modification of the mesoporous matrix is essential because the silanol groups of the silica surface are not selective enough to adsorb drug molecules with different functionalities [20]. Application of mesoporous materials as carriers can solve some problems related with the low solubility and poor bioavailability of the bioactive molecules [21]. Thus, loading of flavanols in nanoporous silica systems can stabilize and protect them from degradation, ensuring high loading capacity [22-27]. Preliminary studies show that immobilization of quercetin in the mesoporous silica, like MCM-41, successfully stabilized quercetin, improving its antioxidant efficacy [28,29,31]. In addition, the increased specific surface area of mesoporous silica particles could eventually improve the bioavailability of bioactive compounds. Application of clinoptilolite zeolite as a carrier of quercetin [29] led to higher cytotoxicity especially for those with particle size up to $200 \mu \mathrm{m}$ and can be used for treatment of different tumor cell lines. The effect of quercetin alone or in complex with $\mathrm{NH}_{2}-\mathrm{MSN}$ (amino modified Mesoporous Silica Nanoparticles) on proliferation of JR8 human melanoma cells was evaluated by Berlier et al. [31] and the results show that the complex with $\mathrm{NH}_{2}-\mathrm{MSN}$ is more effective than quercetin alone, causing about $50 \%$ inhibition of cell proliferation. Data for the development of dermal formulations of quercetin can be found only for carriers like liposome, lipid and similar ones [5-7]. However, there is no information on the effect of quercetin complex with $\mathrm{Zn}$ applied in the preparation of dermal formulations. The antioxidant action of quercetin appears to be a combination of reaction with free radicals and metal ion complexation [32,33]. Up to now particular attention was paid to the complexation of quercetin with $\mathrm{Al}(\mathrm{III})$, which accelerates the iron-driven biological oxidation, such as lipid peroxidation, and can be implicated in neurological diseases [33]. The interaction of flavonoids with biologically relevant cations is not fully understood. It could be expected that the development of quercetin-Zn complex loaded on an appropriate mesoporous silica carrier can additionally stabilize and improve the efficiency of the obtained dermal delivery system.

In the present study the formation of complexes between quercetin and pure siliceous or Zn-modified MCM-41 and SBA-16 mesoporous silica was determined by experimental and theoretical investigations. In-vitro release properties of the obtained delivery systems were studied in respect to their possible application as dermal formulations. 


\section{Materials and methods}

\subsection{Materials}

Cetyl trimethyl ammonium bromide (CTAB) and $\mathrm{PEO}_{106} \mathrm{PPO}_{70}-\mathrm{PEO}_{106}$ (Pluronic F127) were purchased by Aldrich and BASF, respectively. Quercetin (>99.5\%) was provided from Aldrich.

\subsection{Synthesis of SBA-16 silica material}

The parent silica SBA-16 material was synthesized according to the procedure of $\mathrm{Hu}$ et al. [34]. Pluronic F127 triblock copolymer and cetyl trimethyl ammonium bromide (CTAB) were used as templates and tetraethylortosilicate (TEOS) as a silica source. In a typical synthesis, $1.0 \mathrm{~g} \mathrm{F127}$ and $0.12 \mathrm{~g} \mathrm{CTAB}$ were completely dis-solved into a solution of $130 \mathrm{ml}$ water and $10 \mathrm{ml}$ concentrated $\mathrm{HCl}$, followed by the addition of $4.0 \mathrm{ml}$ TEOS under stirring. After $1 \mathrm{~h}$ of stirring at $40{ }^{\circ} \mathrm{C}$, the mixture was heated at $80{ }^{\circ} \mathrm{C}$ for $24 \mathrm{~h}$ under static conditions. The solid product was filtrated, washed with water three times and dried at $50{ }^{\circ} \mathrm{C}$. The template was removed by calcination in air at $550^{\circ} \mathrm{C}$ for $5 \mathrm{~h}$ with a heating rate of $1{ }^{\circ} \mathrm{C} / \mathrm{min}$.

\subsection{Synthesis of MCM-41 silica material}

MCM-41 with $100 \mathrm{~nm}$ particle size was prepared according to the procedure of Huh et al. [35]. This sol-gel procedure is carried out at $80{ }^{\circ} \mathrm{C}$ without co-solvent, in water solution and applying $\mathrm{NaOH}$ as a catalyst. The relative molar composition of the reaction mixture was: 1 TEOS: $0.12 \mathrm{C}_{16} \mathrm{TMABr}$ : $0.31 \mathrm{NaOH}: 1190 \mathrm{H}_{2} \mathrm{O}$. The formed gel was aged at $80{ }^{\circ} \mathrm{C}$ for $2 \mathrm{~h}$, then washed with distilled water until neutral $\mathrm{pH}$, and dried at ambient. Template removal of MCM-41 materials was carried out in air at $550{ }^{\circ} \mathrm{C}$ with $1{ }^{\circ} \mathrm{C} / \mathrm{min}$ rate for $5 \mathrm{~h}$.

\subsection{Functionalization of MCM-41 and SBA-16 by Zn}

An incipient wetness impregnation technique with $\mathrm{Zn}\left(\mathrm{CH}_{3} \mathrm{COO}\right)_{2} \cdot 2 \mathrm{H}_{2} \mathrm{O}$ was applied for loading of 2 or 4 wt. \% zinc. In a typical experiment $300 \mathrm{mg}$ of mesoporous supports (MCM41 or SBA-16) were mixed at room temperature with $1 \mathrm{ml}$ ethanol solution of $\mathrm{Zn}\left(\mathrm{CH}_{3} \mathrm{COO}\right)_{2} \cdot 2 \mathrm{H}_{2} \mathrm{O}-20.14 \mathrm{mg}$ or $40.28 \mathrm{mg}$ for 2 or $4 \mathrm{wt}$. \% zinc, respectively. The precursor salt was decomposed in air at $500{ }^{\circ} \mathrm{C}$ for $3 \mathrm{~h}$ for all samples. Samples were designated as MCM-41Znx or SBA-16Znx where $\mathrm{x}=2$ or 4 wt.\% Zn.

\subsection{Quercetin loading}

Powdered SBA-16 and MCM-41 samples (50 mg) were stirred with quercetin $(50 \mathrm{mg})$ in 1 $\mathrm{ml}$ ethanol till the total evaporation of the solvent. The obtained materials were washed 3 
times with $5 \mathrm{ml}$ water. The samples were dried at $40{ }^{\circ} \mathrm{C}$ overnight. The quercetin loaded SBA-16 and MCM-41 formulations were designated as SBA-16Qu, MCM-41Qu and SBA16ZnxQu, MCM-41ZnxQu, where $x=2$ and 4 wt.\%.

\subsection{Characterization}

X-ray powder diffraction patterns were recorded by a Philips PW 1810/3710 diffractometer with Bragg-Brentano parafocusing geometry applying monochromatized $\mathrm{CuK}_{\mathrm{a}}(\lambda=0.15418$ $\mathrm{nm})$ radiation $(40 \mathrm{kV}, 35 \mathrm{~mA})$ and proportional counter. Simulated powder diffraction pattern of anhydrous quercetin was calculated by Mercury 3.6 software (CCDC) using the CIF file Quer-3 calculated by Filip et al. [36] based on X-ray powder diffraction and NMR data.

Nitrogen physisorption measurements were carried out at $-196{ }^{\circ} \mathrm{C}$ using Tristar 3000 Micromeritics volumetric adsorption analyzer. Before the adsorption analysis, the silica sample was outgassed under vacuum for $2 \mathrm{~h}$ at $200{ }^{\circ} \mathrm{C}$, whereas modified and drug loaded samples were pretreated at $80^{\circ} \mathrm{C}$ for $5 \mathrm{~h}[37,38]$.

TEM images were taken using a MORGAGNI 268D TEM (100 kV; W filament; pointresolution $=0.5 \mathrm{~nm}$ ). Samples were suspended in a small amount of ethanol and a drop of suspension was deposited onto the copper grid covered by carbon supporting film and dried at ambient.

Thermogravimetric measurements were performed with a Setaram TG92 instrument with a heating rate of $5^{\circ} \mathrm{C} / \mathrm{min}$ in air flow.

Attenuated Total Reflection Infrared (ATR-FT-IR) spectra were recorded by means of a Varian Scimitar 2000 FT-IR spectrometer equipped with a MCT (mercury-cadmium-tellur) detector and a single reflection ATR unit (SPECAC "Golden Gate") with diamond ATR element. In general, 128 scans and $4 \mathrm{~cm}^{-1}$ resolution were applied. For all spectra ATRcorrection was performed (Varian ResPro 4.0 software).

\subsection{Quantum-chemical calculations}

Quantum-chemical calculations were used to investigate the interaction between the quercetin molecule and the support. In order to simulate both types of experimentally used mesoporous supports: pristine and exchanged by $\mathrm{Zn}^{2+}$ cations, we employed two different models containing: (i) two silanol groups (denoted as silica/ $2 \mathrm{H}^{+}$) and (ii) $\mathrm{Zn}^{2+}$ cation replacing the protons of silanol groups (denoted as silica $/ \mathrm{Zn}^{2+}$ ). The silica surface was represented by a small cluster model obtained from a zeolite structure. The cluster model consists of two $\mathrm{SiO}_{4}$ tetrahedral, connected by a common $\mathrm{O}$ atom. The dangling bonds were saturated by $\mathrm{H}$ atoms, and the direction of these bonds at the cluster boundary was fixed as obtained in the zeolite structure. The lengths of the corresponding $\mathrm{O}-\mathrm{H}$ bonds were preoptimized, keeping all other atoms in the cluster fixed, followed by an optimization of the cluster with fixed positions of all saturating $\mathrm{H}$ atoms. In the subsequent geometry optimization steps, only the positions of the oxygen centers, $\mathrm{Zn}^{2+}$ cation or silanol groups, and the guest species were relaxed, while 
the positions of terminated $\mathrm{H}$ atoms and $\mathrm{Si}$ atoms were fixed. The quantum-chemical calculations were performed with the program Gaussian09 [39] using hybrid density functional M06-2X [40] with 6e311++G** type of basis sets for all atoms. The solvent effects (all systems are considered solvated in water) were taken into account by the longrange electrostatic effect using the polarizable continuum model (PCM) [41].

\subsection{In-vitro release study}

The in-vitro quercetin release study was performed in buffer $(\mathrm{pH}=5.5)$ at $37^{\circ} \mathrm{C}$. The drugloaded particles $\left(2 \mathrm{mg}\right.$ ) were incubated in $200 \mathrm{ml} \mathrm{pH}=5.5$ solution at $37^{\circ} \mathrm{C}$ under stirring (300 rpm). At appropriate time intervals, $3 \mathrm{ml}$ samples were withdrawn from the release medium and analyzed with UV-Vis spectroscopy at a wavelength of $367 \mathrm{~nm}$. The concentration of the released quercetin was calculated according to the standard curves prepared in $\mathrm{pH}=5.5$ solution $(\mathrm{r}>0.9993)$.

\section{Results and discussion}

\subsection{Material characterization}

Low angle XRD pattern of the parent nanoporous silica samples show the typical intense (100), and (110) reflections for MCM-41 and SBA-16, respectively. The other two weak (110) and (200) lines also appear to confirm the ordered hexagonal structure of MCM-41, however for SBA-16 only the weak (200) reflection can be observed (Supplementary data, S1). Slightly decreased intensity and structure ordering can be observed for samples modified with $\mathrm{Zn}$, however reflections characteristic of crystalline zinc-oxide are not detected at higher angles.

A more significant intensity decrease is observed for the functionalized and quercetin loaded mesoporous samples, which can be explained not only by the decreased amount of silica, but with some pore filling effect by quercetin (Supplementary data, S1), reducing the scattering contrast between the pores and the silica matrix [30].

High angle XRD patterns of quercetin loaded non-modified and Zn modified silica carriers are shown in Fig. 1. Reflections of quercetin can be observed on all samples. This is an evidence that quercetin is not only contained in the pore channels, but can be found on the outer surface of the small nanoparticles or in the voids among the particles. Comparing the diffraction patterns of the parent quercetin dihydrate and the silica loaded quercetin samples, non-identical reflections can be found on them. This phenomenon can be associated with the hydration state of quercetin. Borghetti et al. [42] studied the different crystalline forms of quercetin by high temperature X-ray powder diffraction method. Our samples show identical patterns with their sample called QCTc heat treated at $40{ }^{\circ} \mathrm{C}$, but the exact crystalline structure was not identified. Single crystal data can be found only on di- and monohydrate forms $[43,44]$, however only the powder diffraction pattern generated by the CIF file of 
dihydrate form (Cambridge Structural Database Fef-bex01) is identical with our parent quercetin sample. Based on their X-ray powder diffraction, ${ }^{13} \mathrm{C},{ }^{1} \mathrm{H} \mathrm{NMR}$, and quantum chemical computations data Filip et al. [36] proposed a reliable crystal structure model of anhydrous quercetin with monoclinic system and space group of P21/a. The powder diffraction pattern generated by the CIF file Quer3 presented in their electronic supplementary information gave identical reflections with our samples ( Fig 1). Thus, we can conclude that recrystallization and crystalline water loss of quercetin upon the loading procedure on silica carrier (dissolution in ethanol and heat treatment at $40{ }^{\circ} \mathrm{C}$ ) and formation of anhydrous form can be observed. The presence of silica carrier strongly influences the crystallization of quercetin, because ac-cording to Borghetti et al. and also confirmed by our investigations ( Fig. S2, supplementary data), the heat treatment of bulk quercetin dihydrate does not result consequently in the formation of the above mentioned anhydrous quercetin, but another, yet unidentified polymorph is formed (see heat treatment of QCTa sample at $110{ }^{\circ} \mathrm{C}$ in Ref. [42]). Loading of $\mathrm{Zn}$ on silica carrier did not significantly influence the quercetin loading, also the formation of anhydrous form can be observed.

Nitrogen adsorption and desorption isotherms of the parent, and quercetin loaded nonmodified and Zn-modified MCM-41 and SBA-16 samples are presented in Fig. 2. The calculated textural parameters are summarized in Table 1. The isotherms of the MCM-41 samples are of type IV, reversible, without any hysteresis loop. They exhibit a capillary condensation step at a relative pressure between $\mathrm{p} / \mathrm{p}_{\mathrm{o}}=0.2-0.35$ ( Fig. 2). Textural parameters of the quercetin loaded samples show a significant decrease in the surface area and total pore volume, due to the pore filling by quercetin.

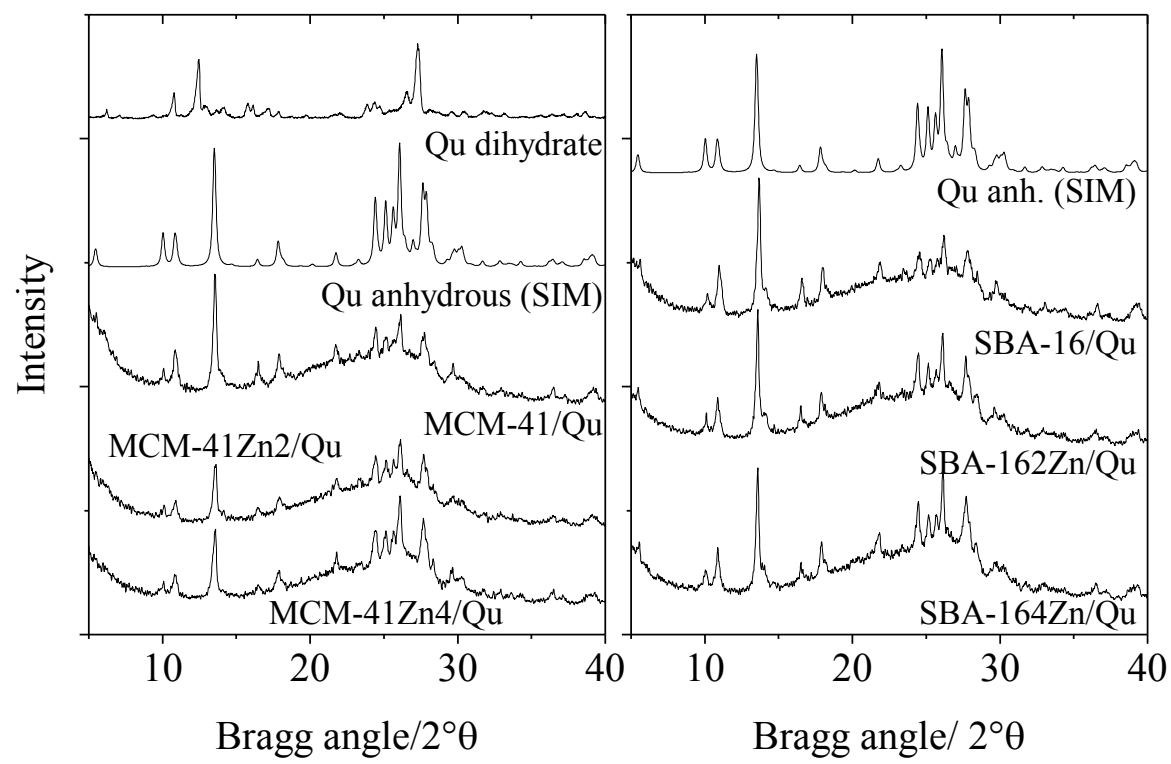

Fig. 1. XRD patterns of quercetin loaded pure silica and Zn modified MCM-41 and SBA-16 formulations compared to pure quercetin. 


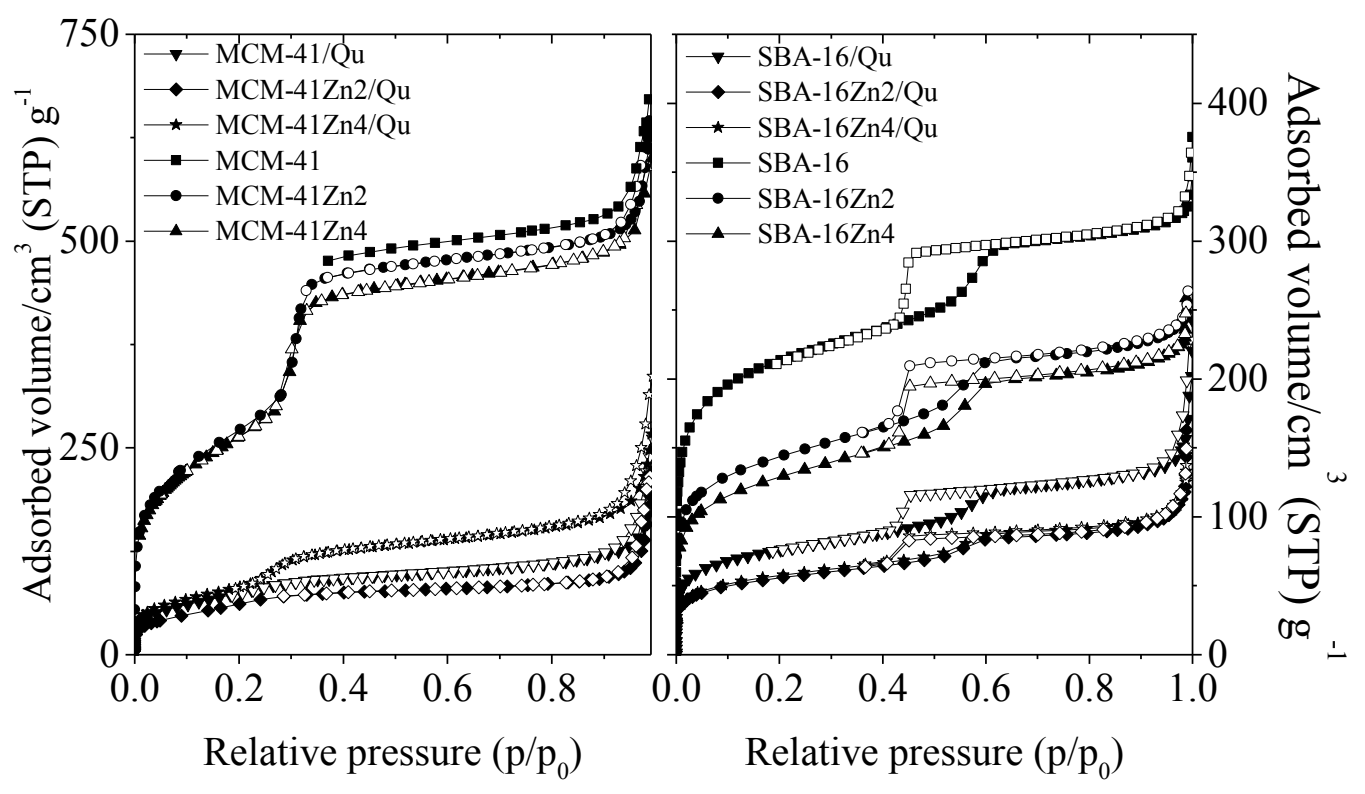

Fig. 2. Nitrogen adsorption and desorption isotherms of the pure silica, $\mathrm{Zn}$ functionalized and quercetin-loaded samples.

Table 1 Textural properties of the non-modified, Zn-functionalized and quercetine loaded mesoporous silicas and the determined amount of quercetin and released $\mathrm{Zn}$.

\begin{tabular}{llllll}
\hline Samples & $\begin{array}{l}\text { BET } \\
\left(\mathrm{m}^{2} / \mathrm{g}\right)\end{array}$ & $\begin{array}{l}\text { Pore vol. } \\
\left(\mathrm{cm}^{3} / \mathrm{g}\right)\end{array}$ & $\begin{array}{l}\mathrm{PD}^{\mathrm{a}} \\
(\mathrm{nm})\end{array}$ & $\begin{array}{l}\text { Quercetin } \\
\text { content (wt.\%) }\end{array}$ & $\begin{array}{l}\text { Released Zn } \\
(\%)\end{array}$ \\
\hline SBA-16 & 787 & 0.49 & 3.6 & - & - \\
SBA-16Zn2 & 522 & 0.36 & 4.6 & - & - \\
SBA-16Zn4 & 469 & 0.34 & 4.8 & - & 2.5 \\
SBA-16/Qu & 276 & 0.21 & 3.5 & 41.1 & - \\
SBA-16Zn2/Qu & 209 & 0.16 & 4.6 & 43.1 & 100 \\
SBA-16Zn4/Qu & 203 & 0.16 & 4.6 & 45.0 & 43 \\
MCM-41 & 1175 & 1.00 & 2.7 & - & - \\
MCM-41Zn2 & 1005 & 0.99 & 2.7 & - & - \\
MCM-41Zn4 & 977 & 0.90 & 2.7 & - & - \\
MCM-41/Qu & 249 & 0.20 & - & 35.0 & - \\
MCM-41Zn2/Qu & 222 & 0.25 & - & 41.8 & 95 \\
MCM-41Zn4/Qu & 278 & 0.29 & 2.3 & 36.6 & 92 \\
\hline
\end{tabular}

${ }^{\mathrm{a}}$ Pore diameter calculated by BJH method.

${ }^{\mathrm{b}} \mathrm{In}$-vitro $\mathrm{Zn}$ release in buffer at $\mathrm{pH}=5.5$. 

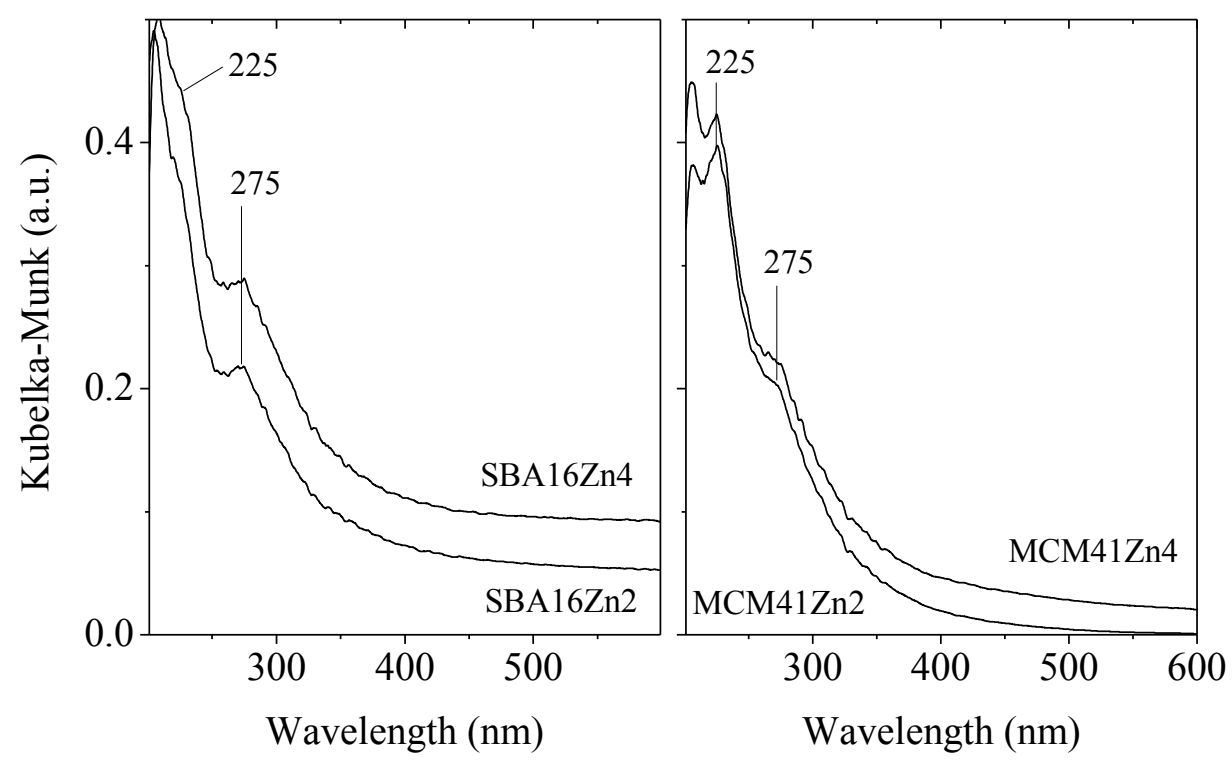

Fig. 3. Diffuse reflectance UV-Vis spectra of pure silica and Zn-containing SBA-16 and MCM-41 samples.

The same phenomena can be observed on SBA-16 carrier. Zn modification reduced the pore volume, the specific surface area and total pore volume by $30 \%$. By modification with $\mathrm{Zn}$, incorporation of $\mathrm{Zn}$ species into the silica matrix can occur and zinc-oxide crystallites can also be formed inside the channels (see UV-Vis spectra below, Fig. 3). SBA-16 has narrow pore entrances, which can be blocked by $\mathrm{ZnO}$ plugs hindering the penetration of nitrogen and consequently quercetin. Their detection by XRD is not possible because of their low amount and crystallite size (below $5 \mathrm{~nm}$ ).

Diffuse reflectance UV-Vis spectroscopic investigation evidenced the formation of $\mathrm{ZnO}$ nanoparticles and incorporation of $\mathrm{Zn}$ into the silica matrix. UV-Vis spectra of the zinc modified silica carriers can be seen in Fig 3. The semiconductor bulk $\mathrm{ZnO}$ phase can be characterized by a broad absorption band at around $350 \mathrm{~nm}$, assigned to the $\mathrm{O}^{2-} / \mathrm{Zn}^{2+}$ ligand to metal charge transfer (LMCT) transition [45,46]. Our Zn-MCM-41 and Zn-SBA-16 samples show absorption bands at 275 and $225 \mathrm{~nm}$ ( Fig. 3). The bands appearing below 230 $\mathrm{nm}$ are generally associated with the charge transfer transitions of framework zinc species with lattice $\mathrm{O}^{2-}$ when metal atoms are incorporated into the silica framework, e.g. in zeolites and nanostructure silicates [46]. Analogically to zeolites and clay minerals, the band around $280 \mathrm{~nm}$ can be considered as encapsulated zinc-oxide nanoparticles with size of 1-2 nm $[47,48]$. Formation of $\mathrm{ZnO}$ nanoparticles is more pronounced on SBA-16, whereas ionic zinc species are dominant on MCM-41 support.

All quercetin loaded samples were characterized by ATR FT-IR method ( Fig. 4), in order to investigate the interaction between the quercetin molecule and the mesoporous carrier. Pure quercetin shows characteristic IR bands of stretching vibrations of aryl ketonic carbonyl 
$\left(v(\mathrm{C}=\mathrm{O})\right.$ at $\left.1655 \mathrm{~cm}^{-1}\right)$ and of aromatic ring $\mathrm{C}=\mathrm{C}$ (at 1600,1561, 1511 and $\left.1432 \mathrm{~cm}^{-1}\right)$. The band at $1360 \mathrm{~cm}^{-1}$ belongs to $-\mathrm{OH}$ bending vibration of the phenols, whereas the band around $1309 \mathrm{~cm}^{-1}$ can be assigned as in-plane bending vibration of aromatic C-H [48,49] (see Fig. 4).

After quercetin loading on MCM-41, the $v(C=O)$ at $1655 \mathrm{~cm}^{-1}$ and the $v(C=C)$ at $1600 \mathrm{~cm}^{-1}$ show an upshift. The splitting of the bands suggests that two types of environment for quercetin are formed. Furthermore, the band intensity of the - $\mathrm{OH}$ bending of phenols around $1360 \mathrm{~cm}^{-1}$ increased. It seems that an interaction between the $-\mathrm{OH}$ groups of the MCM-41 matrix and the phenolic -OH groups of quercetin occurs, which leads to the conjunction loss among the aromatic and pyrone ring in the quercetin molecule. No significant difference was observed for quercetin loaded on pure silica and Zn modified MCM-41 samples. The spectral features of SBA-16Qu spectrum resemble to those of MCM-41Qu. In the presence of $\mathrm{Zn}$, however, the spectra are changed. For detailed analysis of quercetin- $\mathrm{Zn}$ interactions, an impregnation procedure by $\mathrm{Zn}$ was applied for pure quercetin ( Fig. $4 \mathrm{C}$ ). Regarding the spectrum of Qu:Zn 7\%, the slight upwards shift of the $v(C=O)$ and $v(C=C)$ bands prove the coordination of $\mathrm{Zn}$ to quercetin. Moreover, new bands at 1456 and $1207 \mathrm{~cm}^{-1}$ arise, indicating that at least one -OH group is involved in the coordination. For Qu:Zn 1:1 complex, however, the $v(\mathrm{C}=\mathrm{O})$ band is significantly diminished, whereas a new band at $1272 \mathrm{~cm}^{-1}$ corresponding to $v(\mathrm{C}-\mathrm{O})$ has increased. This implies that the coordination of the metal ion occurs between the carbonyl group and the $-\mathrm{OH}$ group of ring $\mathrm{C}$ [50-52]. The shifts in the $\mathrm{C}=\mathrm{C}$ aromatic ring vibrations are more pronounced, suggesting a stronger coordination. As for the $\mathrm{Zn}$ modified SBA-16 samples, small new bands can be observed in the spectra at 1492, 1461 and $1265 \mathrm{~cm}^{-}$

${ }^{1}$ wavenumbers, corresponding to the formation of $\mathrm{Zn}$-quercetin complex involving also both the $-\mathrm{OH}$ and the $\mathrm{C}=\mathrm{O}$ groups.

In conclusion, FT-IR spectroscopic investigations evidenced that on non-modified mesoporous silica quercetin is coordinated via its phenolic $\mathrm{OH}$ groups to the silanol groups of the silica matrix by hydrogen bonding. In the presence of zinc, incorporated on the surface of silica walls or as nanoparticles in the channels, a zinc-quercetin complex is formed, mainly by chelating phenolic -OH groups. It is interesting to note that in the case of $\mathrm{Zn}$ functionalized SBA-16, the ketonic carbonyl group of the quercetin is also involved in the coordination, presumably resulting in a stronger interaction.

\subsection{Quercetin loading and in vitro release}

Quercetin was loaded on the mesoporous silica carriers by incipient wetness impregnation from solution. Ethanol was chosen as a solvent, because of the high solubility of the quercetin in it. The loaded amount of quercetin was investigated by thermogravimetric method ( Fig. 5). TG data are presented in Table 1. Data show high loading on all samples with 35-45 wt. \% quercetin content. The loaded amount of quercetin is higher for zinc containing samples for both supports. 

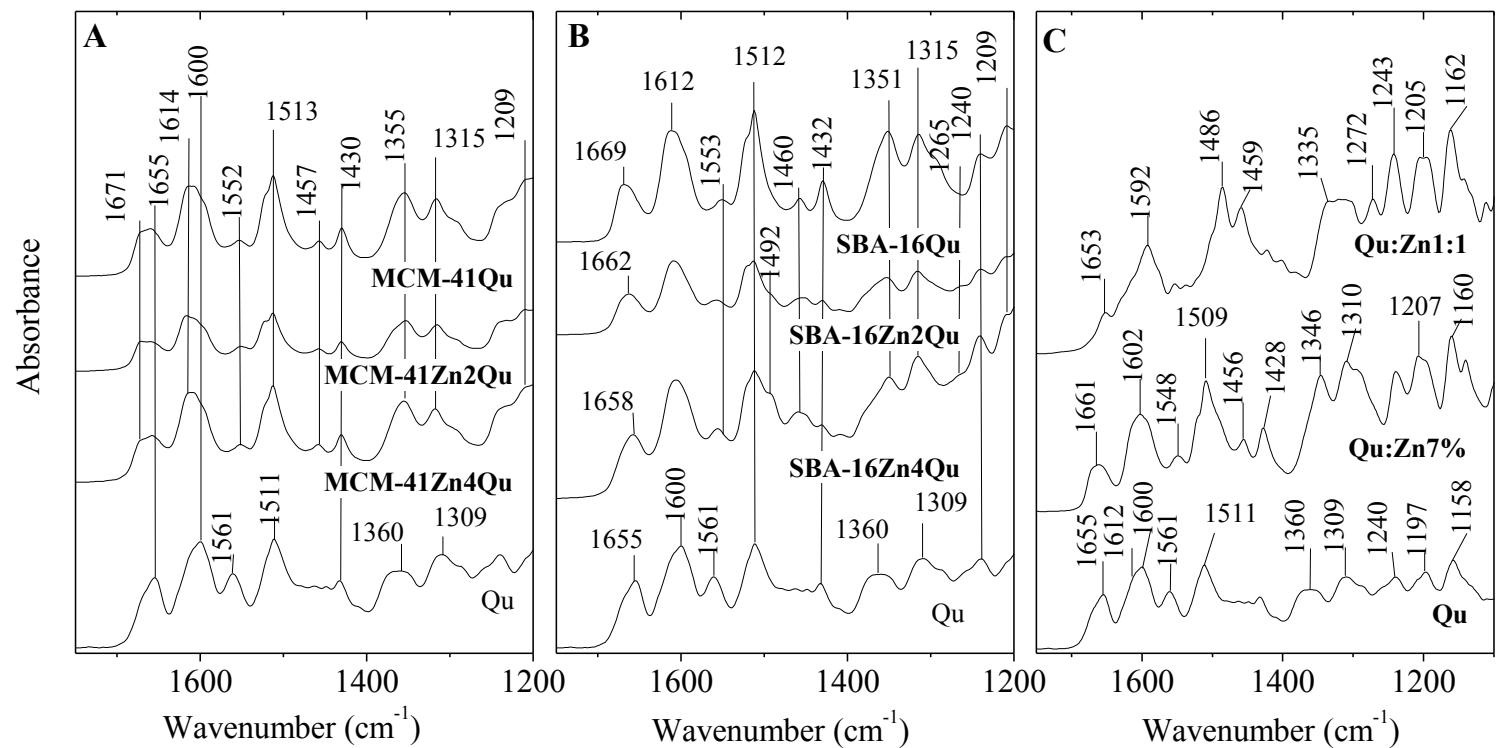

Fig. 4. ATR FT-IR spectra of quercetin and quercetin loaded pure silica and Zn-MCM-41 and Zn-SBA-16 samples.
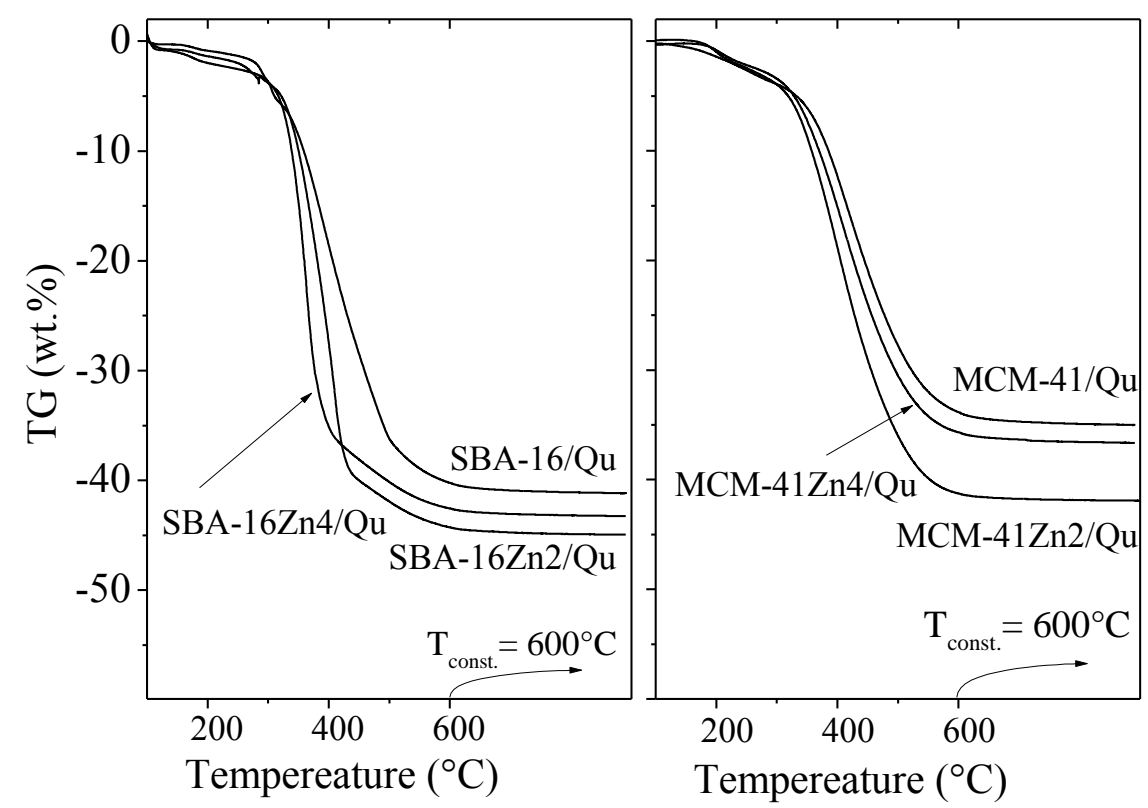

Fig. 5. TG curves of quercetin loaded pure silica and Zn modified MCM-41 and SBA-16 silica carriers. 
Loading of quercetin on silica carriers slightly influenced its decomposition temperature by shifting it to $25{ }^{\circ} \mathrm{C}$ lower values. For zinc containing samples this shift is more pronounced, reaching $40{ }^{\circ} \mathrm{C}$ for SBA-16Zn4 sample ( Fig. 5).

Quercetin release ( Fig. 6) was investigated in simulated body fluid at $\mathrm{pH}=5.5$ which is typical for dermal formulations. Quercetin loaded mesoporous silicas show burst release with $77 \%$ of released quercetin in $30 \mathrm{~min}$, whereas for zinc containing silica carriers it was lowered to $40 \%$. Total release was observed in $6 \mathrm{~h}$ for non-modified MCM-41 and SBA-16 materials, and also for $4 \%$ zinc containing MCM-41 sample. However, release of quercetin was slower for zinc containing samples for the entire studied period and total release could not be reached with Zn-SBA-16 formulations. The latter can be explained by the bimodal pore structure of SBA-16, consisting of narrower pore entrances and bigger cavities and by the complexation with zinc evidenced by the FT-IR method. Quercetin molecules penetrating into the bigger pores are reacting with the encapsulated zinc nanoparticles and their release is hindered by the narrower entrances.

The release of zinc was also significantly increased with quercetin loading. $\mathrm{Zn}$ release of the SBA-16Zn4 sample was $0.05 \mathrm{mg} / \mathrm{L}$, which corresponds to $2.5 \mathrm{wt}$.\% of the total zinc content. However, in the presence of quercetin the released amount of zinc dramatically increased ( Table 1) to 43-100 wt. \%. This effect can also be associated with the formation of $\mathrm{Zn}$ quercetin complex, making the metal content of the silica carrier soluble. The dissolution of zinc was higher on Zn-SBA-16 samples than on Zn-MCM-41 ones. This observation is in accordance with FT-IR data suggesting the formation of Zn-quercetin complex predominantly on the SBA-16 structure. This can be explained by the formation of a higher amount of ionic zinc species ( $\equiv \mathrm{Si}-\mathrm{O}-\mathrm{Zn}-\mathrm{O}-\mathrm{Si} \equiv$ ) incorporated into the silica framework of MCM-41 evidenced by UV-Vis spectra. Our quantum-chemical calculations also show that the reaction of $\mathrm{Zn}^{2+}$ in silica: $\mathrm{ZnO}+$ Silica/2 $\mathrm{H}^{+} /$Silica/ $/ \mathrm{Zn}^{2+}+\mathrm{H}_{2} \mathrm{O}$ is strongly exothermic by almost $300 \mathrm{~kJ} / \mathrm{mol}$. Hence, such $\mathrm{Zn}$ species are strongly adsorbed and cannot be leached and even the coordinated quercetin cannot "pull it out". Zinc release is lower on samples containing a higher amount of zinc for both supports. This can be explained by the formation of zinc oxide nanoparticles filling the channels, resulting in their restricted accessibility to quercetin. The preservation of particle morphology of MCM-41 and SBA-16 was evidenced by TEM images ( Fig. 7). The presence of bigger $\mathrm{Zn}$ nanoparticles on SBA-16Zn4Qu is shown as well, and this result is in good accordance with the UV-Vis data ( Fig. 3). 


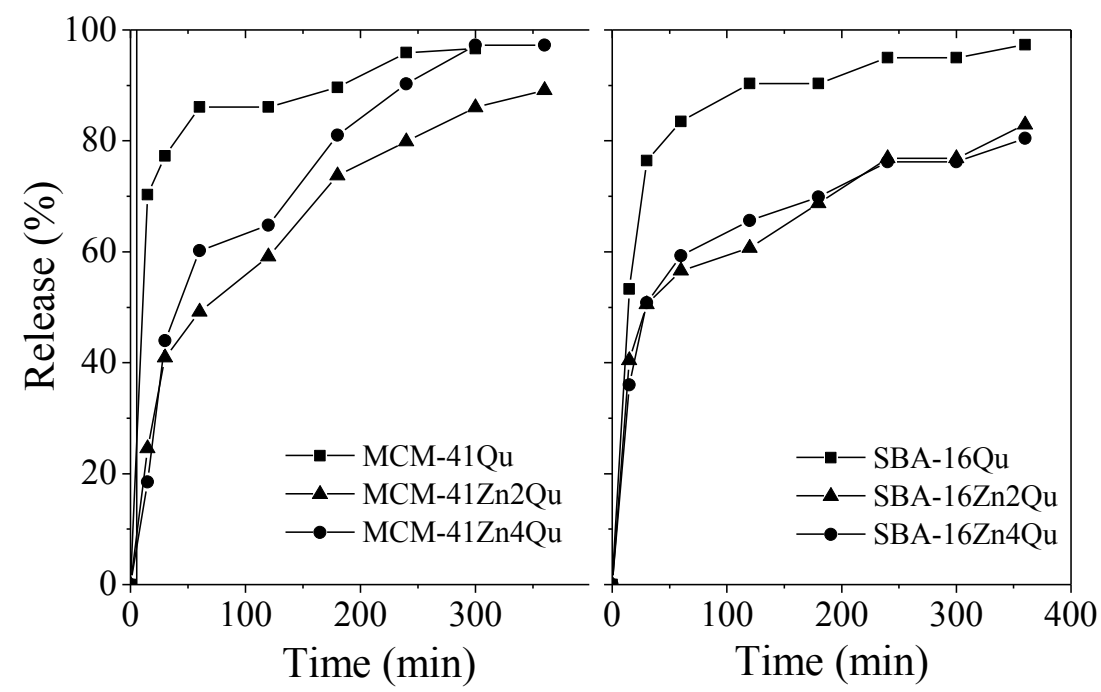

Fig. 6. In-vitro release profiles of quercetin loaded pure silica and zinc modified SBA-16 and MCM-41 samples at $\mathrm{pH}=5.5$.

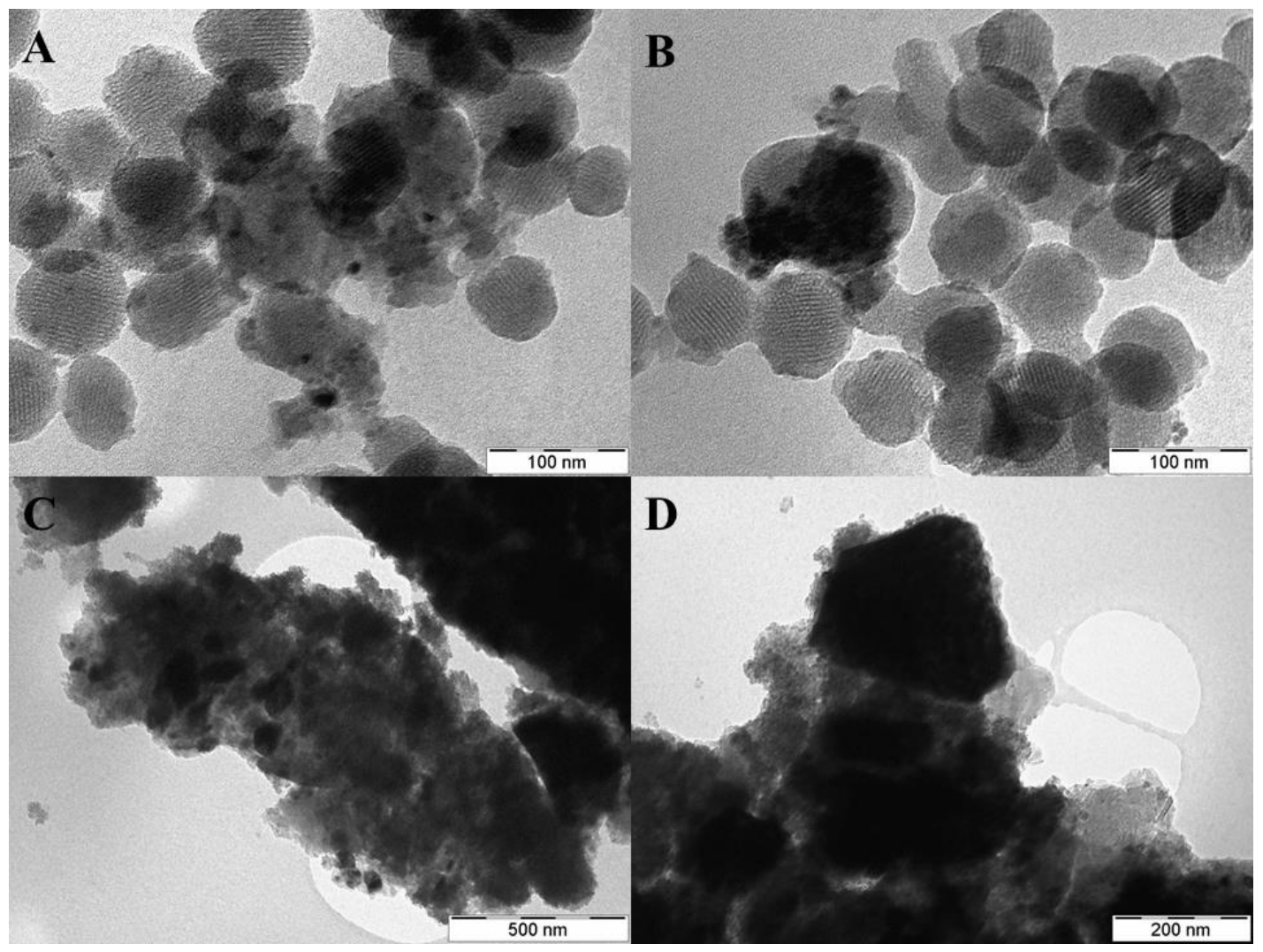

Fig. 7. TEM images of MCM-41Zn4Qu (A, B) and SBA-16Zn4Qu (C, D) samples. 


\subsection{Modeling of adsorption complexes of quercetin on silica clusters containing silanol groups or $\mathrm{Zn}^{2 b}$ cations}

We modeled three different types of coordination of quercetin on the isolated cluster models Silica/2H $\mathrm{H}^{+}$and Silica/ $\mathrm{Zn}^{2+}$ (see Section 2.6) ( Fig. 8). In complex 1 , the $\mathrm{Zn}^{2+}$ or $\mathrm{H}^{+}$ cations interact with two neighboring phenolic $\mathrm{OH}$ groups from the quercetin molecule, while in complexes 2 and 3 the cations interact with $\mathrm{C}=\mathrm{O}$ and $\mathrm{OH}$ groups. In the complexes with intact silanol groups the $\mathrm{H}^{+}$cations coordinate to two $\mathrm{O}$ atoms from the quercetin molecule. In all modeled cases the $\mathrm{Zn}^{2+}$ cations coordinate to two $\mathrm{O}$ atoms from the silica cluster and two $\mathrm{O}$ atoms from the quercetin molecule. In addition, the three complexes of Silica/ $\mathrm{Zn}^{2+}$ with quercetin were considered in three different geometries: square planar, tetrahedral and octahedral. In the last case two additional water molecules were adsorbed to the $\mathrm{Zn}^{2+}$ cation in order to achieve coordination number six. Formation of all possible intramolecular H-bonds leads to the most energetically favorable conformation of all three complexes.

Table 2 outlines the relative energies of the adsorption complexes of quercetin on the silica cluster. Among the complexes where $\mathrm{Zn}^{2+}$ is four-coordinated, the most stable ones are the planar and tetrahedral complexes 2 and 3 . Their relative stability varies within $10 \mathrm{~kJ} / \mathrm{mol}$. The complexes of type 1 are less stable than the other two types of complexes by $10-30 \mathrm{~kJ} / \mathrm{mol}$. When $\mathrm{Zn}^{2+}$ has octahedral coordination, the complex 3 is more stable than the other two complexes by about $25 \mathrm{~kJ} / \mathrm{mol}$. In contrast, the interaction of the two silanol groups from the pristine silica cluster with the two neighboring phenolic $\mathrm{OH}$ groups of quercetin (complex 1) is more favorable by 24 and $25 \mathrm{~kJ} / \mathrm{mol}$ with respect to complexes 2 and 3. In summary, our calculations showed that complexes of type 2 and 3, with coordination via carbonyl and hydroxyl groups, are the most stable when quercetin is adsorbed on $\mathrm{Zn}^{2+}$ cations, while the complex 1 , where the coordination is via two hydroxyl groups, is the most stable when the drug molecule is adsorbed on the silanol groups. These results are in line with our experimental findings.

In order to check whether quercetin prefers to be adsorbed to or released from the pristine or $\mathrm{Zn}^{2+}$ modified silica surface, the following three equilibriums were considered:

Silica/ $2 \mathrm{H}^{+}\left(\mathrm{H}_{2} \mathrm{O}\right)_{2}+$ quercetin $\rightleftharpoons$ Silica/2 $\mathrm{H}^{+}$(quercetin) $+2 \mathrm{H}_{2} \mathrm{O}$ (eq. 1)

Silica $/ \mathrm{Zn}^{2+}\left(\mathrm{H}_{2} \mathrm{O}\right)_{2}+$ quercetin $\rightleftharpoons$ Silica/ $/ \mathrm{Zn}^{2+}$ (quercetin) $+2 \mathrm{H}_{2} \mathrm{O}$ (eq. 2)

Silica/ $\mathrm{Zn}^{2+}\left(\mathrm{H}_{2} \mathrm{O}\right)_{2}+$ quercetin $\rightleftharpoons$ Silica/ $\mathrm{Zn}^{2+}\left(\mathrm{H}_{2} \mathrm{O}\right)_{2}$ (quercetin) (eq. 3)

In equilibrium 2, we considered two cases where the quercetin molecule forms tetrahedral and square planar complexes with the Silica/ $/ \mathrm{Zn}^{2+}$ model. Table 2 also summarizes the energy of the three adsorption processes considered (eqs. 1-3). For the most stable complexes Silica/ $2 \mathrm{H}^{+}$(quercetin) and Silica/ $/ \mathrm{Zn}^{2+}$ (quercetin) adsorption processes are endothermic, by 21 $\mathrm{kJ} / \mathrm{mol}$, or essentially enthalpy neutral, $-1 \mathrm{~kJ} / \mathrm{mol}$, respectively, while for the octahedral 

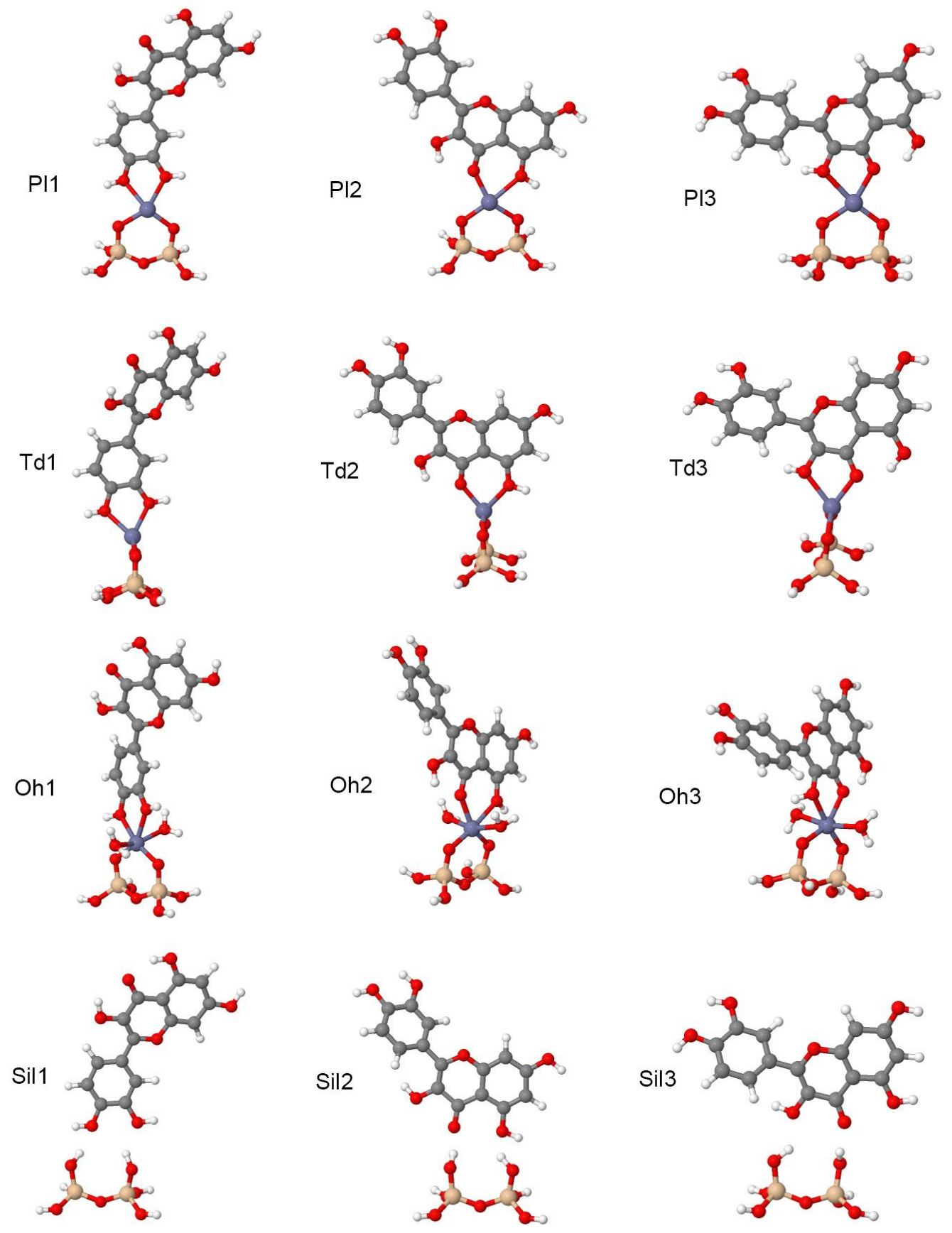

Fig. 8. Optimized complexes of quercetin on silica cluster containing $\mathrm{Zn}^{2 \mathrm{~b}}$ cation: Complex1/Square planar (P11), Complex-2/Square planar (Pl2), Complex-3/Square planar (Pl3), Complex-1/Tetraedral (Td1), Complex-2/Tetraedral (Td2), Complex-3/Tetraedral (Td3), Complex-1/Octahedral (Oh1), Complex-2/Octahedral (Oh2), Complex-3/Octahedral (Oh3), or silanol groups: Complex-1/silanol (Sil1), Complex-2/silanol (Sil2), and Complex-3/silanol (Sil3). Color notation: Si- orange, Zn- blue, O- red, C- gray, H- white. (For interpretation of the references to color in this figure legend, the reader is referred to the web version of this article.) 
complexes they are exothermic by $30-50 \mathrm{~kJ} / \mathrm{mol}$. The results show that the adsorption of quercetin to the $\mathrm{Zn}^{2+}$ cation is more exothermic than to the silanol groups. Hence, we can conclude that quercetin binds stronger to the $\mathrm{Zn}^{2+}$ cation than to the silanol groups and this result can rationalize our experimental result that the release of this molecule is easier from the silicate samples containing only surface silanol groups than from $\mathrm{Zn}$ modified samples.

Table 2 Relative energies, $\mathrm{E}_{\text {rel }}(\mathrm{kJ} / \mathrm{mol})$, of the adsorption complexes of quercetin on silica surface, containing silanol groups or modified with $\mathrm{Zn}^{2+}$ cation. The values are calculated with respect to the most stable complex in each series. Energies, DE (in $\mathrm{kJ} / \mathrm{mol}$ ) of the four considered reactions of quercetin adsorption to a zeolite fragment containing $\mathrm{Zn}^{2+}$ or two silanol groups are also shown.

\begin{tabular}{llcl}
\hline Structures & notation $^{\text {a }}$ & $\mathrm{E}_{\text {rel }}$ & $\Delta \mathrm{E}$ \\
\hline Complex-1/Square planar & $\mathrm{Pl} 1$ & 20 & $20^{\mathrm{c}}$ \\
Complex-2/Square planar & $\mathrm{Pl} 2$ & 6 & $6^{\mathrm{c}}$ \\
Complex-3/Square planar & $\mathrm{Pl} 3$ & 5 & $4^{\mathrm{c}}$ \\
Complex-1/Tetraedral & $\mathrm{Td} 1$ & 29 & $28^{\mathrm{c}}$ \\
Complex-2/Tetraedral & $\mathrm{Td} 2$ & 10 & $10^{\mathrm{c}}$ \\
Complex-3/Tetraedral & $\mathrm{Td} 3$ & 0 & $-1^{\mathrm{c}}$ \\
Complex-1/Octahedral & $\mathrm{Oh} 1$ & 23 & $-28^{\mathrm{d}}$ \\
Complex-2/Octahedral & $\mathrm{Oh} 2$ & 24 & $-28^{\mathrm{d}}$ \\
Complex-3/Octahedral & $\mathrm{Oh3}$ & 0 & $-52^{\mathrm{d}}$ \\
Complex-1/silanol & $\mathrm{Sil1}$ & 0 & $21^{\mathrm{b}}$ \\
Complex-2/silanol & $\mathrm{Sil} 2$ & 24 & $46^{\mathrm{b}}$ \\
Complex-3/silanol & $\mathrm{Sil3}$ & 25 & $47^{\mathrm{b}}$ \\
\hline
\end{tabular}

\footnotetext{
${ }^{\mathrm{a}}$ The notation is used in Fig. 7.

${ }^{\mathrm{b}}$ Equilibrium 1.

${ }^{\mathrm{c}}$ Equilibrium 2.

${ }^{\mathrm{d}}$ Equilibrium 3.
}

\section{Conclusions}

High loading capacities of quercetin on pure silica and Zn-containing mesoporous MCM-41 and SBA-16 materials were achieved by incipient wetness impregnation method. For the first time the formation of more stable $\mathrm{Zn}$ quercetin complexes loaded on mesoporous silica materials was evidenced. In-vitro release experiments at $\mathrm{pH}=5.5$ showed faster quercetin release from MCM-41 and SBA-16 systems in comparison to $\mathrm{Zn}$ modified ones, due to the stronger interaction of quercetin molecule with the $\mathrm{Zn}^{2+}$ cations than with the silanol groups on the silica surface. Stability against light sensitivity was also significantly improved by 
loading quercetin on the nanostructured silica carriers. Spectroscopic data suggested the formation of Zn-quercetin complex on the zinc modified supports. Textural and UV-Vis investigations evidenced the incorporation of zinc into the silica structure and formation of oxide nanoparticles encapsulated in the channels. Pore filling of the bimodal pore system of SBA-16 structure by zinc oxide nanoparticles influenced its quercetin release profile. Our experimental and theoretical results also showed that the quercetin molecule is bound to the silica surface via different functional groups, depending on the cations available on the surface. On the pure silica surface, the silanol groups interact with the two neighboring phenolic $\mathrm{OH}$ groups (ring $\mathrm{B}$, complex 1). In the case of $\mathrm{Zn}$-modified silicate surface the quercetin molecule is adsorbed to the $\mathrm{Zn}^{2+}$ cations via neighboring carbonyl and hydroxyl groups (ring $\mathrm{C}$, complexes 3 ). If water molecules are available in the systems, most probably octahedral complexes; otherwise tetrahedral or square planar complexes will be formed. The studied delivery systems are promising as efficient dermal formulations.

\section{Acknowledgements}

Financial support from the Bulgarian-Hungarian Inter-Academic Exchange Agreement is greatly acknowledged. I. Trendafilova thanks the project funded by Bulgarian Academy of Sciences for young scientists support, proposal 91/2016.

Appendix A. Supplementary data

Supplementary data related to this article can be found at http:// dx.doi.org/10.1016/j.micromeso.2016.04.001.

\section{References}

[1] I. Erlund, Nutr. Res. 24(10) (2004) 851-874.

[2] Y. Chen, A. Islam, P. Abraham, P. Deuster, Nutr. Res. 34(7) (2014) 623-629.

[3] G. R. Beecher, B. A. Warden H. Merken, Proc. Soc. Exp. Biol. Med. 220 (1999) 267270.

[4] J. Kuhnau, World Rev. Nutr. Diet. 24 (1976) 117-191.

[5] A. P. Landi-Librandi, T. N. Chrysostomo, A. E. C. S. Azzolini, C. M. MarzocchiMachado, C. A. de Oliveira, Y. M. Lucisano-Valim, J. Lipos. Res. 22 (2012) 89-99. 
[6] M. Sun, S. Nie, X.Pan, R. Zhang, Z. Fan, S.Wang, Colloids Surf.B Biointerfaces 113C (2013) 15-24.

[7] G. Chen-Yu, Y. Chun-Fen, L. Qi-Lu, T. Qi, X. Yan-Wei, L. Wei-Na, Z. Guang-Xi, Int. J. Pharm. 430 (2012) 292-298.

[8] T. Pralhad, K. Rajendrakumar, J. Pharm. Biomed. Anal., 34 (2004) 333-339.

[9] A. Kumari, S.K. Yadav, Y.B. Pakade, B. Singh, S.C. Yadav, Colloids Surf. B Biointerfaces 80 (2010) 184-192.

[10] R. Fang, H. Jing, Z. Chai, G. Zhao, S. Stoll, F.Ren, F. Liu, X. Leng, J. Nanobiotechnol. $9(2011) 19$.

[11] M. Y. Moridani, J. Pourahmad, H. Bui, A. Siraki, P. O'Brien, J. Free Radic. Biol. Med. 34 (2003) 243-253.

[12] J.Tan, B. Wang, L. Zhu, Bioorganic \& Medicinal Chemistry 17 (2009) 614-620.

[13] C. Caddeo, O. Díez-Sales, R. Pons, C. Carbone, G. Ennas, G. Puglisi, A. M. Fadda, M. Manconi, J. Coll. Inter. Sci. 461 (2016) 69-78.

[14] S. Jeon, Ch. Yoo. S. N. Y. Park, Colloids and Surfaces B: Biointerfaces 129 (2015) 714.

[15] D. Liu, H. Hu, Zh. Lin, D. Chen, Y. Zhu, Sh. Hou, X. Shi, J. Photochem, Photobiology B: Biology 127 (2013) 8-17.

[16] M. Vallet-Regí, A. Ramila, R.P. del Real, J. Perez-Pariente, Chem. Mater. 13 (2001) 308-311.

[17] Sh. Wang, Micropor. Mesopor. Mater. 117 (2009) 1-9.

[18] M. Manzano, V. Aina, C. O. Arean, F. Balas, V. Cauda, M. Colilla, M.R. Delgado, M. Vallet-Regí, Chem. Eng. J. 137 (2008) 30-37. 
[19] Ch.-H. Lin, Sh.-H. Cheng, W.-N. Liao, P.-R. Wei, P.-J. Sung, Ch.-F. Weng, Ch.-H. Lee, Int. J. Pharm. 429 (2012) 138-147.

[20] P. Horcajada, A. Ramila, G. Ferey, M. Vallet-Regí, Solid State Sci. 8 (2006) 12431249.

[21] M. Popova, A. Szegedi, K. Yoncheva, S. Konstantinov, G.P. Petrova, H.A.Aleksandrov, G.N. Vayssilov, P. Shestakova, Micropor. Mesopor. Mater. 198 (2014) 247-255.

[22] M. Popova, Á. Szegedi, V. Mavrodinova, J. Mihály, Sz. Klébert, N.Benbassat, K. Yoncheva, J. Solid State Chem. 219 (2014) 37-42.

[23] E.H. Gokce, E. Korkmaz, E. Dellera, G. Sandri, M. C. Bonferoni, O. Ozer, Inter. J. Nanomed. 7 (2012) 1841-1850.

[24] M. Sessa, R. Tsao, R. Liu, G. Ferrari, F. Donsì, J. Agric. Food Chem. 59 (2011) 1235212360.

[25] K. Sonaje, J. L. Italia, G. Sharma, V. Bhardwaj, K. Tikoo, M. N. V. Ravi Kumar, Pharm. Research 24 (5) (2007) 899-908.

[26] G. Nest, O. Le Caille, M. Woudstra, S. Roche, F. Guerlesquin, D. Lexa, Inorganica Chimica Acta 357 (2004) 775-784.

[27] Ch.-H. Tsai, J. L. Vivero-Escoto, I. I. Slowing, I-J. Fang, B. G. Trewyn, V. S.-Y. Lin, Biomaterials 32 (2011) 6234-6244.

[28] S. Sapino, E. Ugazio, L. Gastaldi, I. Miletto, G. Berlier, D. Zonari, S. Oliaro-Bosso, European J. Pharm. Biopharm. 89 (2015) 116-25;

[29] V. Tomecková, M. Reháková, G. Mojzišová, J. Magura, T. Wadsten, K. Zelenáková, Micropor. Mesopor. Mater. 147 (2012) 59-67.

[30] N. Gargiulo, I. Attianese, G. G. Buonocore, D. Caputo,M. Lavorgna, G. Mensitieri, M. Lavorgna, Micropor. Mesoporous. Mater. 167 (2013) 10-15. 
[31] G. Berlier, L. Gastaldi, E. Ugazio, I. Miletto, P. Iliade, S. Sapino, J. Coll. Inter. Sci. 393 (2013) 109-118.

[32] J. P. Cornard, J. C. Merlin, J. Inorg. Biochem., 92 (2002) 19-27

[33] A. Ahmedova, K. Paradowska, I. Wawer, J. Inorg. Biochem. 110 (2012) 27-35

[34] Y. Hu, Zh. Zhi, Q. Zhao, Ch. Wu, P. Zhao, H. Jiang, T. Jiang, S. Wang, Micropor. Mesopor. Mater. 147(1) (2012) 94-101.

[35] S. Huh,J. W. Wiench, J.-Ch. Yoo, M. Pruski, V. S.-Y. Lin, Chem. Mater. 15 (2003) 4247-4256.

[36] xX. Filip, I.-G. Grosu, M. Miclaus, C. Filip, Cryst. Eng. Comm. 15 (2013) 4131-4142.

[37] A. Szegedi, M. Popova, I. Goshev, J. Mihaly, J. Solid State Chem. 184 (2011) 12011207.

[38] A. Szegedi, M. Popova, K. Yoncheva, J. Makk, J. Mihaly, P. Shestakova, J. Mater. Chem. B 2 (2014) 6283-6292.

[39] Gaussian 09, Revision D.01, Frisch, M. J.; Trucks, G. W.; Schlegel, H. B.; Scuseria, G. E.; Robb, M. A.; Cheeseman, J. R.; Scalmani, G.; Barone, V.; Mennucci, B.; Petersson, G. A.; Nakatsuji, H.; Caricato, M.; Li, X.; Hratchian, H. P.; Izmaylov, A. F.; Bloino, J.; Zheng, G.; Sonnenberg, J. L.; Hada, M.; Ehara, M.; Toyota, K.; Fukuda, R.; Hasegawa, J.; Ishida, M.; Nakajima, T.; Honda, Y.; Kitao, O.; Nakai, H.; Vreven, T.; Montgomery, J. A., Jr.; Peralta, J. E.; Ogliaro, F.; Bearpark, M.; Heyd, J. J.; Brothers, E.; Kudin, K. N.; Staroverov, V. N.; Kobayashi, R.; Normand, J.; Raghavachari, K.; Rendell, A.; Burant, J. C.; Iyengar, S. S.; Tomasi, J.; Cossi, M.; Rega, N.; Millam, J. M.; Klene, M.; Knox, J. E.; Cross, J. B.; Bakken, V.; Adamo, C.; Jaramillo, J.; Gomperts, R.; Stratmann, R. E.; Yazyev, O.; Austin, A. J.; Cammi, R.; Pomelli, C.; Ochterski, J. W.; Martin, R. L.; Morokuma, K.; Zakrzewski, V. G.; Voth, G. A.; Salvador, P.; 
Dannenberg, J. J.; Dapprich, S.; Daniels, A. D.; Farkas, Ö.; Foresman, J. B.; Ortiz, J. V.; Cioslowski, J.; Fox, D. J. Gaussian, Inc., Wallingford CT, 2009.

[40] Y. Zhao, D. G. Truhlar, Theor. Chem. Acc. 120 (2008) 215-241.

[41] J. Tomasi, B. Mennucci, R. Cammi, Chem. Rev. 105 (2005) 2999-3093.

[42] G. S. Borghetti, J. P. Carini, S. B. Honorato, S.B. Honorato, A. P. Ayala, J. C. F. Moreira, V. L. Bassani, Thermochimica Acta 539 (2012) 109-114.

[43] G.-Z. Jin, Y. Yamagata, K. Tomita, Acta Crystallogr. Sect. C 46 (1990) 310-313.

[44] S. Domagała, P. Munshi, M. Ahmed, B. Guillot. Ch. Jelsch, Acta Cryst. B67 (2011) 6378.

[45] L. Wang, Sh. Sang, Sh. Meng, Y. Zhang, Y. Qi, Zh. Liu, Materials Letters 61 (8-9) (2007) 1675-1678.

[46] S. G. Hur, T. W. Kim, S. J. Hwang, S. H. Hwang, J. H. Yang, J. H. Choy, J. Phys. Chem. B. 110 (4) (2006) 1599-16604.

[47] E. A. Alarcón, A. L. Villa, C. M. de Correa, Micropor. Mesopor. Mater. 122 (2009) $208-215$.

[48] M. Heneczkowski, M. Kopacz, D. Nowak, A. Kuzniar, Infrared Acta Pol. Pharm.58 (2001) 415-20.

[49] M. Catauro, F. Papale, F. Bollino, S. Piccolella, S. Marciano, P. Nocera, S. Pacifico, Sci. Technol. Adv. Mater.16 (2015) 035001.

[50] Y. Liu, M. Guo, Molecules 20 (2015) 8583-8594.

[51] Sh. Yang, B. Yin, L. Xu, B. Gao, H. Sun, L. Du, Y. Tang, W. Jianga F. Cao, Anal. Methods 7 (2015) 4546-4551.

[52] T.-H. Wu, F.-L. Yen, L.-T. Lin, T.-R. Tsai, Ch.-Ch. Lin, Th.-M. Cham, Inter. J. Pharm. 346 (2008) 160-168. 